\title{
Papilloedema due to Chiari I malformation
}

\author{
Jason Chao Zhang, ${ }^{1,2}$ Belal Bakir, ${ }^{1,3}$ Andrew Lee, ${ }^{1,2,3,4,5}$ Sushma S Yalamanchili1,4 \\ ${ }^{1}$ Ophthalmology Department, The Methodist Hospital, Houston, Texas, United States; \\ ${ }^{2}$ Baylor College of Medicine, Houston, Texas, United States; \\ ${ }^{3}$ Ophthalmology Department, University of Texas Medical Branch, Galveston, Texas, United States; \\ ${ }^{4}$ Ophthalmology Department, Weill Cornell Medical College, New York, United States; \\ ${ }^{5}$ Ophthalmology Department, The University of lowa Hospitals and Clinic, lowa City, lowa, United States
}

Correspondence to Sushma S Yalamanchili, syalamanchili2@tmhs.org

\section{Summary}

The Chiari I malformation is a congenital abnormality characterised by downward displacement of the cerebellar tonsils through the foramen magnum into the cervical spine. It presents clinically most often in young adult women. Known ocular manifestations linked to Chiari I consist primarily of oculomotor paresis with cranial nerve VI palsy and convergence/divergence abnormalities. Papilloedema is a rare manifestation of Chiari I with a clinical presentation often similar to that of idiopathic intracranial hypertension. To highlight this unusual complication, the authors report a 64-year-old female who developed papilloedema as the only presenting neurological symptom resulting from a Chiari I malformation.

\section{BACKGROUND}

The Chiari I malformation is a congenital malformation characterised by downward displacement of the cerebellar tonsils through the foramen magnum into the cervical spine. ${ }^{1}$ Patients with Chiari I commonly present with headache/neck pain and symptoms related to cranial nerve compression, brainstem compression, cerebellar dysfunction, myelopathy and syringomelia. Ocular manifestations consist primarily of oculomotor paresis with cranial nerve VI palsy and convergence/divergence abnormalities. Papilloedema is a rare but known manifestation of Chiari I malformation, with a literature search indicating eight previous articles on papilloedema in adult patients with Chiari I. ${ }^{2-9}$
The presentation of patients with Chiari I and papilloedema often resembles that of idiopathic intracranial hypertension (IIH). Like IIH, Chiari I preferentially affects women and manifests clinically most often in young adulthood. ${ }^{1}$ Furthermore, Chiari I normally does not present with significant ventriculomegaly. In a report by Milhorat et al, ${ }^{2}$ seven of nine patients with Chiari I and papilloedema had no evidence of ventricular enlargement via MRI.

\section{CASE PRESENTATION}

A 64-year-old Hispanic woman was referred to our clinic with a 5 -week history of headaches, blurry vision and fatigue. The patient also experienced a 6-day episode of diplopia that resolved spontaneously. She often felt

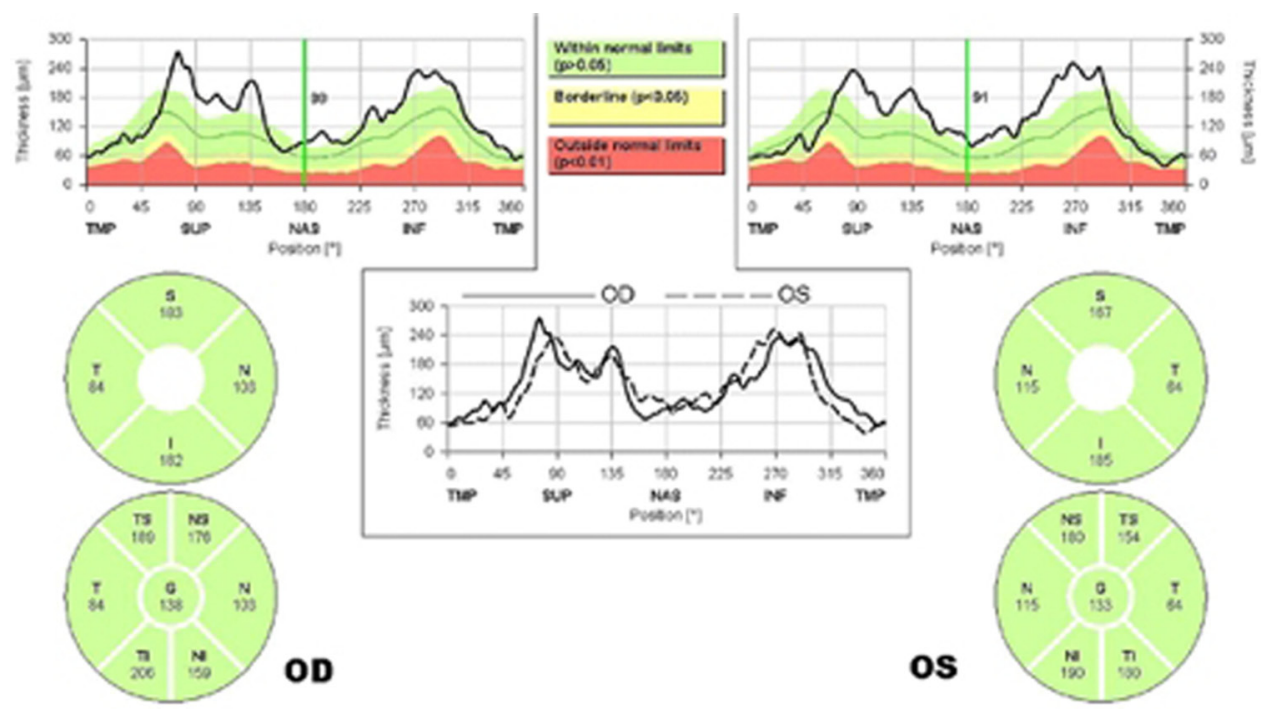

Figure 1 Optical coherence tomography of optic nerves demonstrates elevated retinal nerve fiber layer thickness bilaterally with global averages of 138 microns $\mathrm{OD}$ and 133 microns OS (normal $100+/-10$ microns). 

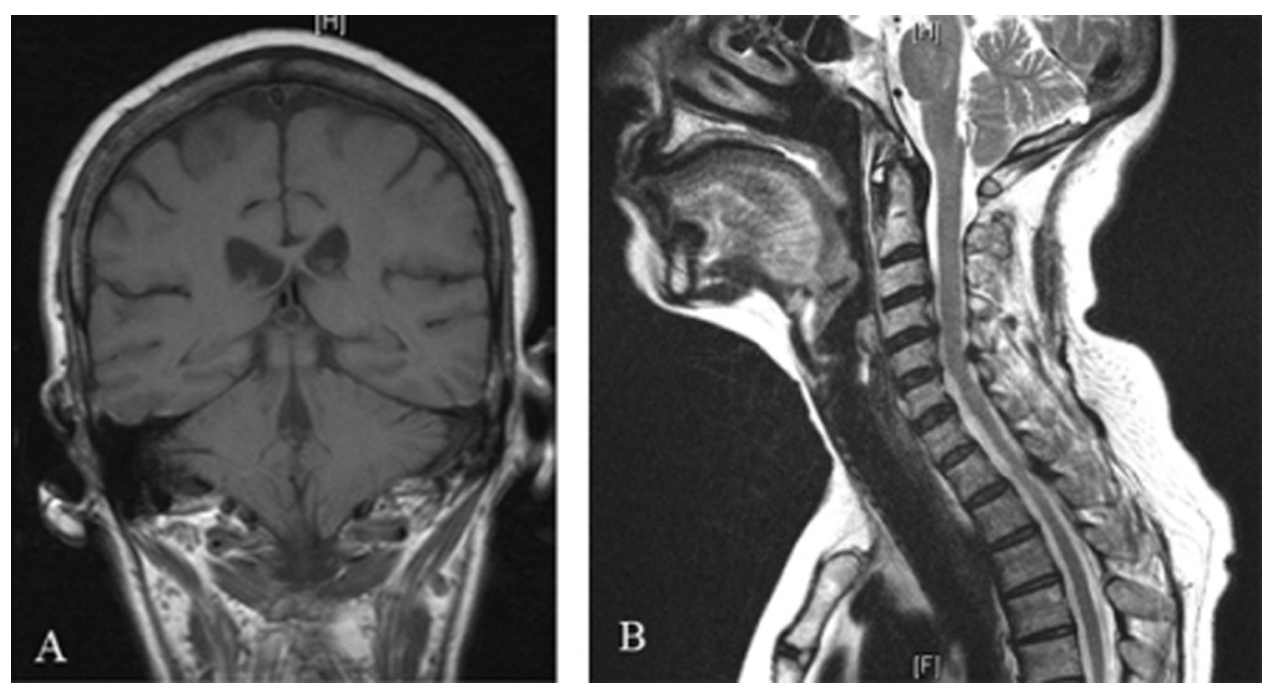

Figure 2 Coronal T-1 weighted MRI (A) and sagittal T-2 weighted MRI (B) of the brain and spine demonstrate a Chiari type I malformation with an $8 \mathrm{~mm}$ cerebellar tonsil herniation below the foramen magnum down to the level of the odontoid process.

'pressure' behind her eyes. Medical history was significant for hypothyroidism, hyperlipidemia, sinusitis and anxiety. She had a body mass index (BMI) of 22.7.

On neuro-ophthalmic examination, best visual acuity was $20 / 25$ OU. Pupils were $6.0 \mathrm{~mm}$ in dark and $5.5 \mathrm{~mm}$ in light with no relative afferent pupillary defect detected. Motility, external and intraocular pressure exams were normal. Slit lamp biomicroscopy was normal except for $2+$ bilateral nuclear sclerotic cataracts consistent with $20 / 25$ vision OU. Dilated funduscopic exam was significant for grade 1 optic disc oedema OU. Humphrey visual field showed superior and inferior arcuate nerve fibre layer type defects with mean deviations of $-13.87 \mathrm{~dB}$ $\mathrm{OD}$ and $-14.25 \mathrm{~dB}$ OS. Optical coherence tomography indicated bilateral optic nerve fibre layer elevation with global averages of 138 microns OD and 133 microns OS (figure 1).

\section{INVESTIGATIONS}

MRI imaging of the brain (figure 2) showed no evidence of ventricular/cistern enlargement or intracranial lesions, eliminating the possibilities of malignant obstruction and deep vein thrombosis. However, imaging studies do indicate an $8 \mathrm{~mm}$ herniation of the cerebellar tonsils past the level of the foramen magnum, findings consistent with the diagnosis of Chiari I malformation.

\section{DIFFERENTIAL DIAGNOSIS}

Bilateral optic disc oedema with preserved visual acuity and nerve fibre layer loss is typically the consequence of papilloedema. ${ }^{10}$ The differential diagnosis for disc oedema in this patient includes intracranial mass lesion leading to hydrocephalus, IIH, cerebral venous outflow obstruction, malignant hypertension and meningeal lesions.

The diagnosis of IIH is primarily one of exclusion and is characterised as having signs and symptoms of elevated intracranial pressure (ICP) (papilloedema, headaches, diplopia, etc), a normal neurologic examination, an unremarkable cerebrospinal fluid (CSF) analysis and an absence of ventricular enlargement or intracranial spaceoccupying lesions on imaging studies. ${ }^{11} \mathrm{IIH}$ typically affects women in their 20s and 30s who are obese.

MRI imaging revealed a Chiari I malformation as the principal cause of papilloedema in this case.

\section{TREATMENT}

The only therapy shown to be consistently effective in treatment of patients with Chiari I and papilloedema is suboccipital decompression, opening the fourth ventricle outlet to restore pressure and CSF flow. In a retrospective study of four patients with Chiari I and papilloedema, Valphiades et a $\beta$ reported that surgical decompression via suboccipital craniectomy, upper cervical laminectomy and duraplasty proved beneficial in resolving headaches and visual problems in all patients reported. The same study noted that acetazolamine, a diuretic treatment option for IIH, was ineffective during treatment of these patients' symptoms.

While Chiari I is treated surgically, IIH is typically treated medically with weight loss and diuretic therapy. ${ }^{11}$ Diagnosis and treatment of IIH may require CSF drainage and, with failure of medical therapy, a permanent shunting procedure. In patients misdiagnosed with IIH, lumbar punctures performed to relieve ICP have been shown to precipitate severe neurological and visual deterioration in Chiari I patients. ${ }^{3-5} 7$

\section{OUTCOME AND FOLLOW-UP}

Our patient underwent suboccipital craniotomy with C1 laminecotmy and expansile duraplasty with surgical decompression. Six weeks post-surgery, the patient's headaches had resolved. Her visual acuity remained 20/25 OU and the optic disc oedema had resolved to optic atrophy OU. Repeat visual fields showed mild improvement in the nerve fibre layer scotomas bilaterally with $\mathrm{MD}$ values of $-10.78 \mathrm{~dB}$ OD and $-12.87 \mathrm{~dB}$ OS. 


\section{DISCUSSION}

It is often difficult to differentiate clinically between Chiari I with papilloedema and IIH due to similarities in patient presentations. Our case does highlight one important distinction - while patients with IIH are typically obese, ${ }^{11}$ patients with Chiari I often have a normal BMI. In previous reports on papilloedema in Chiari I, an initial misdiagnosis of IIH was common, resulting in an episode of neurological and visual decline. ${ }^{3-5}$ CT imaging has been shown to be much more unreliable than MRI in detecting Chiari I. ${ }^{6}$ Furthermore, Chiari I is sometimes interpreted as a coincidental finding in papilloedema patients. The authors recommend that MRI studies of the saggital craniocervical junction should be performed in all patients with suspected IIH prior to any CSF studies.

One distinct aspect of this case was the age at which the patient presented with symptoms. While previous reports on papilloedema in Chiari I have mainly documented patients in their 20s-30s (the typical age at which Chiari I presents clinically), older patients have been reported. To the best of our knowledge, this is the first reported case of papilloedema associated with Chiari I malformation in a patient above the age of 60 .

The pathogenesis of papilloedema in Chiari I is not well-known. One previous report speculated that posterior fossa crowding results in CSF flow delay, causing transiently increased ICP following pressure pulses (Valsalva maneuvers, etc). ${ }^{4}$ Papilloedema has been reported in cases of varying degrees of tonsilar herniation, in one report ranging from 7 to $22 \mathrm{~mm}^{3}$. It is likely that there exists some structural congenital abnormality that predisposes to development of papilloedema independent of the cerebellar morphology.

Prognosis for Chiari I patients with papilloedema following surgical decompression is also not well-documented. While Valphiades et al noted full resolution of symptoms following surgery in all four of their patients, ${ }^{3}$ our patient's visual symptoms improved but she was left with a residual field defect and bilateral optic nerve atrophy.

\section{Learning points}

- Papilloedema is a rare but important manifestation of Chiari I malformation that may present as the only neurological symptom.

- It is often difficult to differentiate clinically between Chiari I with papilloedema and IIH due to similarities in patient presentations. MRI imaging of the saggital craniocervical junction should be performed in all patients with IIH.

- Surgical decompression of the posterior fossa is the only treatment shown to be consistently effective in Chiari I patients with papilloedema.

Competing interests None.

Patient consent Obtained.

\section{REFERENCES}

1. Cai C, Oakes WJ. Hindbrain herniation syndromes: the Chiari malformations (I and II). Semin Pediatr Neurol 1997;4:179-91.

2. Milhorat TH, Chou MW, Trinidad EM, et al. Chiari I malformation redefined: clinical and radiographic findings for 364 symptomatic patients. Neurosurgery 1999;44:1005-17.

3. Vaphiades MS, Eggenberger ER, Miller NR, et al. Resolution of papilledema after neurosurgical decompression for primary Chiari I malformation. Am J Ophthalmol 2002:133:673-8.

4. Choudhari KA, Cooke C, Tan MH, et al. Papilloedema as the sole presenting feature of Chiari I malformation. Br J Neurosurg 2002;16:398-400.

5. Vrabec TR, Sergott RC, Savino PJ, et al. Intermittent obstructive hydrocephalus in the Arnold-Chiari malformation. Ann Neurol 1989;26:401-4.

6. Vaphiades MS, Braswell R. Resolution of Chiari I malformation following acetazolamide therapy. Semin Ophthalmol 2007:22:9-11.

7. Lancione RR Jr, Kosmorsky GS. When does low mean high? Isolated cerebral ventricular increased intracranial pressure in a patient with a Chiari I malformation. J Neuroophthalmol 2001;21:118-20.

8. Troeber L, Löw U, Jonescu-Cuypers C, et al. [Massive papilledema combined with subretinal bleeding in one eye as first appearance of Arnold-Chiarimalformation type I in adolescence]. Klin Monbl Augenheilkd 2011;228:480-2.

9. Pardo Muñoz A, Reche Sainz JA, Sanz López A, et al. [A case of papilledema and Arnold-Chiari type I malformation]. Arch Soc Esp Oftalmol 2002; 77:449-53.

10. Sergott RC. Diagnosis and management of vision-threatening papilledema. Semin Neurol 1986;6:176-84.

11. Digre KB, Corbett JJ. Idiopathic intracranial hypertension (pseudotumor cerebri): a reappraisal. Neurologist 2001;7:2-67.

This pdf has been created automatically from the final edited text and images.

Copyright 2011 BMJ Publishing Group. All rights reserved. For permission to reuse any of this content visit

http://group.bmj.com/group/rights-licensing/permissions.

BMJ Case Report Fellows may re-use this article for personal use and teaching without any further permission.

Please cite this article as follows (you will need to access the article online to obtain the date of publication).

Zhang JC, Bakir B, Lee A, Yalamanchili SS. Papilloedema due to Chiari I malformation. BMJ Case Reports 2011;10.1136/bcr.08.2011.4721, date of publication

Become a Fellow of BMJ Case Reports today and you can:

- Submit as many cases as you like

- Enjoy fast sympathetic peer review and rapid publication of accepted articles

- Access all the published articles

- Re-use any of the published material for personal use and teaching without further permission

For information on Institutional Fellowships contact consortiasales@bmjgroup.com

Visit casereports.bmj.com for more articles like this and to become a Fellow 